Supporting Information

\title{
Impact of Surface Hydrophilicity on \\ Electrochemical Water Splitting
}

Byung Keun Kim, ${ }^{1}$ Myung Jun Kim, ${ }^{2, *}$ and Jae Jeong Kim ${ }^{1, *}$

${ }^{1}$ School of Chemical and Biological Engineering, Institute of Chemical Processes, Seoul National

University, Gwanak 1, Gwanak-ro, Gwanak-gu, Seoul, 08826, Republic of Korea

${ }^{2}$ Department of Applied Chemistry, Kyung Hee University, Yongin, 17104, Republic of Korea

\section{Corresponding Authors}

myungjun.kim@khu.ac.kr (MJK), jjkimm@snu.ac.kr(JJK)

\section{Contents}

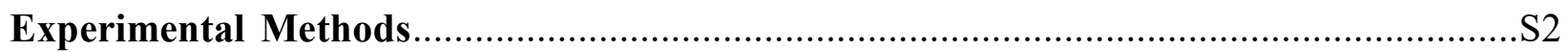

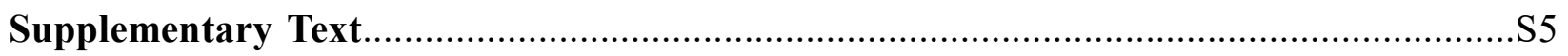

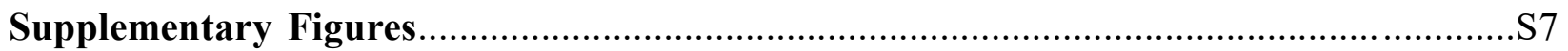

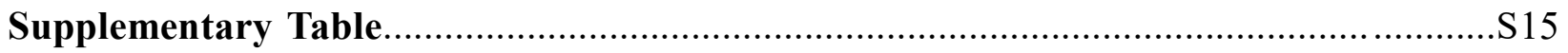

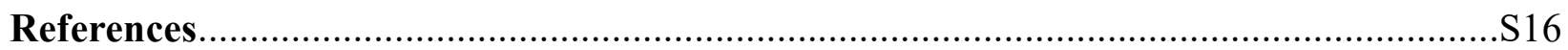




\section{Experimental Methods}

\section{Electroless Deposition of the NiP Films}

Nickel phosphorous (NiP) films were prepared on $\mathrm{Cu}$ foils via electroless deposition. The $\mathrm{Cu}$ foil $(100 \mu \mathrm{m}$ thick, SKC) was cut into $2 \mathrm{~cm} \times 2 \mathrm{~cm}$ pieces and then sonicated for $15 \mathrm{~min}$ in acetone to remove organic residues. $\mathrm{Cu}$ surface oxide was removed to improve the uniformity of electroless deposition by dipping the $\mathrm{Cu}$ foils in $20 \mathrm{mM}$ citric acid and $35 \mathrm{mM} \mathrm{KOH}$ aqueous solution for 5 min. The Sn sensitization and Pd activation were successively conducted by dipping the pretreated $\mathrm{Cu}$ foils in an aqueous solution containing $36 \mathrm{mM} \mathrm{SnCl}_{2}$ and $0.68 \mathrm{M} \mathrm{HCl}$ for $15 \mathrm{~min}$ and a solution of $0.5 \mathrm{mM} \mathrm{PdCl}_{2}$ and $34 \mathrm{mM} \mathrm{HCl}$ solution for $5 \mathrm{~min}$. The samples were washed with deionized water between each step. The solutions for electroless deposition were prepared with $80 \mathrm{mM}$ nickel sulfate hexahydrate $\left(\mathrm{NiSO}_{4} \cdot 6 \mathrm{H}_{2} \mathrm{O}\right), \quad 150 \mathrm{mM}$ sodium hypophosphite monohydrate $\left(\mathrm{NaH}_{2} \mathrm{PO}_{2} \cdot \mathrm{H}_{2} \mathrm{O}\right), 100 \mathrm{mM}$ phosphoric acid $\left(\mathrm{H}_{3} \mathrm{PO}_{4}\right)$, and four different complexing agents (see Table S1). The $\mathrm{pH}$ of the electroless deposition solutions was set to 5 by adding $\mathrm{NaOH}$. The electroless deposition was carried out by dipping the $\mathrm{Sn}-\mathrm{Pd}$ treated $\mathrm{Cu}$ foils in the solutions for 20 min at $70^{\circ} \mathrm{C}$. All chemicals were obtained from Sigma Aldrich and used as received.

\section{Characterization of the NiP Films}

The surface morphologies and elemental compositions of the prepared NiP films were investigated using a field emission scanning electron microscope (FE-SEM, Merlin Compact, ZEISS) and energy dispersive X-ray spectroscopy (EDS, Merlin Compact, ZEISS), respectively. To investigate the chemical states of $\mathrm{Ni}$ and $\mathrm{P}, \mathrm{X}$-ray photoelectron spectroscopy (XPS, Sigma Probe, VG Scientific) was performed with a monochromatic Al Ka (1486.6 eV) X-ray source. The XPS spectra were further calibrated with the C 1s peak $(284.8 \mathrm{eV})$. X-ray diffraction (XRD, D8 
Advance, BRUKER MILLER) was employed to investigate the crystal structures of the NiP films using a $\mathrm{Cu} \mathrm{K} \alpha_{1}$ monochromatic X-ray, with a scan rate of $2 \% \mathrm{~min}$. The surface roughness and the height of the NiP protrusions formed on the surface were measured using an atomic force microscope (AFM, Park XE Series, Park Systems). The water contact angle was measured with a contact angle analyzer (DO4010 Easy drop, KRUSS), dropping $10 \mu \mathrm{L}$ of water droplet from a 2.8 $\mathrm{cm}$ height. The contact angle was recorded when the elapsed time after the water drop reached 1 min. The surface area of the NiP films was electrochemically obtained (i.e., electrochemically active surface area, ECSA) from the capacitive charging/discharging current obtained through cyclic voltammetry. Cyclic voltammetry of the NiP films was performed in an aqueous electrolyte of $1.0 \mathrm{M} \mathrm{KOH}$ by cycling the electrode potential between $-50 \mathrm{mV}$ and $50 \mathrm{mV}$ (vs. open circuit potential, OCP) at scan rates of 10,20,30,40, and $50 \mathrm{mV} / \mathrm{s}$. The capacitive current was obtained by plotting half of the anodic and cathodic current difference versus scan rate (Figure S3).

\section{Electrochemical Measurements for Hydrogen Evolution Reaction (HER)}

A standard three-electrode electrochemical cell was established for electrochemical analyses. In order to perform electrochemical analyses, the prepared $\mathrm{NiP}$ films were cut and pasted on a $\mathrm{Cu}$ rotating disk electrode (RDE) using silver paste. The exposed geometric area of the NiP electrode was $0.1257 \mathrm{~cm}^{2}$. A Pt wire and a saturated calomel electrode (SCE, sat'd $\mathrm{KCl}$ ) were used as the counter and reference electrodes, respectively. All electrochemical measurements were performed using a potentiostat (PATSTAT ${ }^{\text {TM }}$ MC, Princeton Applied Research). The electrode potentials were converted into the reversible hydrogen electrode (RHE) using the following equation: $\mathrm{E}_{\mathrm{RHE}}=\mathrm{E}_{\mathrm{SCE}}$

$+0.242+0.05916 \times \mathrm{pH}$. An aqueous electrolyte of $1.0 \mathrm{M} \mathrm{KOH}$ was used for electrochemical measurements. 
The polarization curves were acquired by sweeping the electrode potential from $0.2 \mathrm{~V}$ to $-0.6 \mathrm{~V}$ (vs. SCE) at a scan rate of $5 \mathrm{mV} / \mathrm{s}$. Chronopotentiometry was performed at $-10 \mathrm{~mA} / \mathrm{cm}^{2}$ current density for $800 \mathrm{~s}$ with $(2000 \mathrm{rpm})$ and without $(0 \mathrm{rpm})$ rotation. Another chronopotentiometry profile was obtained by increasing the rotation speed of the RDE from 0 to 400, 1000, and 2000 $\mathrm{rpm}$ at each $100 \mathrm{~s}$ operation. The current densities for this experiment were 5, 10, 20, and 30 $\mathrm{mA} / \mathrm{cm}^{2}$. Because each sample has a different ECSA (Figures $2 \mathrm{f}$ and S3f), the applied current density was calculated by multiplying the current density by ECSA for each NiP film.

The electrodes for the full cell test were prepared by attaching NiP-1 and NiP-4 on the stainless plate, exposing a geometric area of $0.2827 \mathrm{~cm}^{2}$. In this experiment, we used a two-electrode system consisting of two identical NiP films that acted as the cathode and anode. The current densities were 20 and $100 \mathrm{~mA} / \mathrm{cm}^{2}$, and the current densities were the applied current normalized using the ECSA of each NiP film.

\section{In Situ Visualization of Gas Bubbles on the NiP Films}

In situ visualization was performed with horizontal and vertical electrode configurations. For both cases, the electrolyte was $1.0 \mathrm{M} \mathrm{KOH}$ and the current density was $-10 \mathrm{~mA} / \mathrm{cm}^{2}$. A threeelectrode cell ( $\mathrm{NiP}$ as the working electrode, $\mathrm{Pt}$ wire as the counter electrode, and SCE as the reference electrode) was used for both experiments. No agitation was applied during the experiment. The evolution of $\mathrm{H}_{2}$ on the horizontal NiP films was recorded using a charge-coupled device (CCD) camera (FM40, KRUSS). In the vertical electrode configuration, an optical microscope (ASTSV5-XYS, Sometech) was used to record the growth and departure of $\mathrm{H}_{2}$ bubbles on the NiP films. The average bubble size and bubble size distribution were obtained from at least 100 bubbles captured from the videos (see also Videos S1 and S2). 


\section{Supplementary Text}

\section{Estimation of Bubble Size at the Departure from Vertical Electrodes}

Figure S6a suggests a brief scheme of the bubble departure from the vertical electrode. ${ }^{1,2}$ As in the horizontal configuration, $\mathrm{H}_{2}$ bubbles grow larger until the sum of y-direction forces $\left(F_{y}\right)$ maintains equilibrium. The force balance equation in the y-direction is thus given as:

$$
\sum F_{y}=F_{s y}+F_{d u, y}+F_{d}+F_{b}
$$

where $F_{s y}$ is the y-directional surface tension force, $F_{d u, y}$ is the unsteady drag force derived from the asymmetrical shape of the bubble, $F_{d}$ is the drag in the flow direction, and $F_{b}$ is the buoyancy force. Klausner et al. earlier reported the y-direction surface tension force as: ${ }^{3}$

$$
F_{s y}=-2 r_{w} \sigma \frac{\pi\left(\theta_{a}-\theta_{r}\right)}{\pi^{2}-\left(\theta_{a}-\theta_{r}\right)^{2}}\left[\sin \theta_{a}+\sin \theta_{r}\right]
$$

where $\sigma$ is the surface tension of the electrolyte $(47.3 \mathrm{~N} / \mathrm{m}) . r_{w}$ is the contact radius between a bubble and surface, which is given as

$$
r_{w}=r_{d} \cdot \sin \theta_{m}
$$

The contact angle $\theta_{m} \theta_{m}=\theta_{a}-\theta_{d}=\theta_{r}+\theta_{d}$ was used to evaluate the advancing $\left(\theta_{a}\right)$ and receding $\left(\theta_{r}\right)$ contact angles. Assuming a stagnant system allows us to neglect all drag forces. Then, equation ( $\mathrm{S} 1)$ is given as $F_{s y}=-F_{b}$. The buoyancy force of the bubble at departure is given as

$$
F_{b}=\frac{4}{3} \pi r_{d}^{3} \Delta \rho g
$$

where $\Delta \rho$ is the difference between the density of the liquid and gas $\left(1050.91 \mathrm{~kg} / \mathrm{m}^{3}\right)$ and $g$ is the gravitational acceleration $\left(9.8 \mathrm{~m} / \mathrm{s}^{2}\right)$.

Thus, equation (S1) can be written by combining equations (S2) and (S4) as:

$$
\left(2 r_{d} \sigma \sin \theta_{m}\right) \frac{\pi\left(\theta_{a}-\theta_{r}\right)}{\pi^{2}-\left(\theta_{a}-\theta_{r}\right)^{2}}\left[\sin \theta_{a}+\sin \theta_{r}\right]=\frac{4}{3} \pi r_{d}^{3} \Delta \rho g
$$

Rearranging equation (S5) enables the expression of $r_{d}$ as: 


$$
r_{d}=\sqrt{\frac{3 \sigma \sin \theta_{m} \frac{\theta_{d}}{\pi^{2}-\theta_{d}^{2}}\left[\sin \theta_{a}+\sin \theta_{r}\right]}{2 \Delta \rho g}}
$$

Calculating the contact diameter by adopting $\theta_{d}=2.5^{\circ}$ gives the bubble size, represented as solid circles in Figure S6b. The difference between the calculated and measured bubble sizes is also confirmed in the vertical configuration, as shown in Figure S6b. 


\section{Supplementary Figures}

a

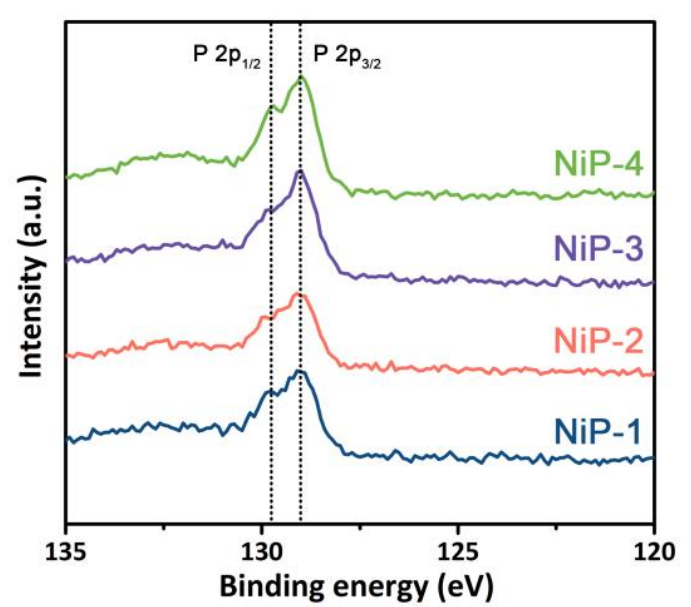

b

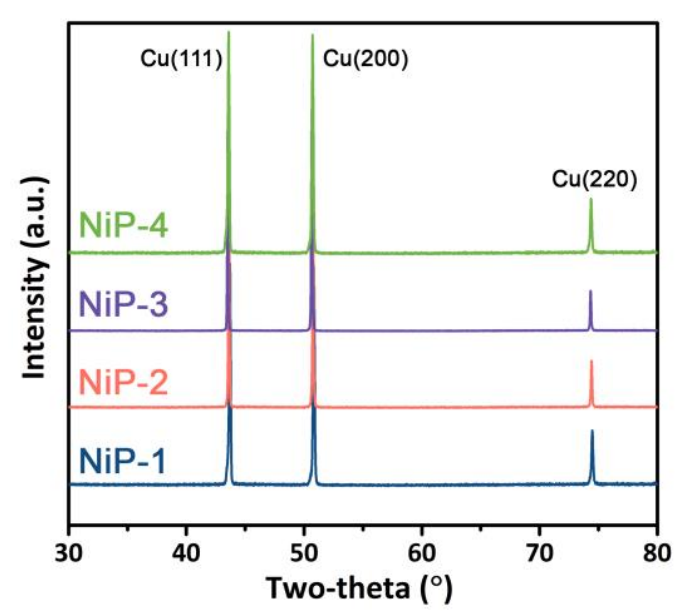

Figure S1. (a) XPS spectra of P 2p and (b) XRD patterns for the NiP films. 


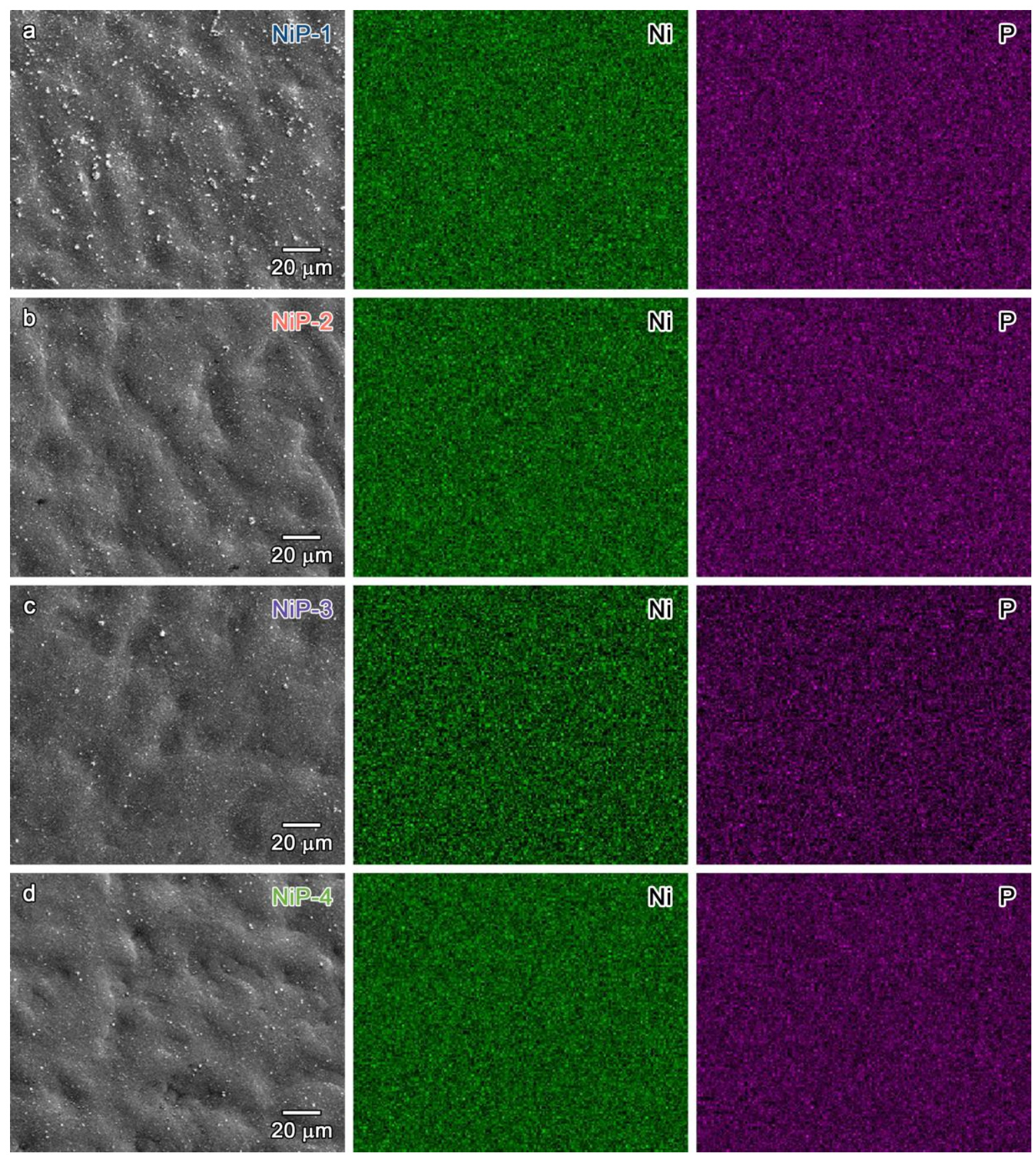

Figure S2. SEM images and EDS mapping results of Ni and P (from left to right) for (a) NiP-1, (b) NiP-2, (c) NiP-3, and (d) NiP-4 films. 

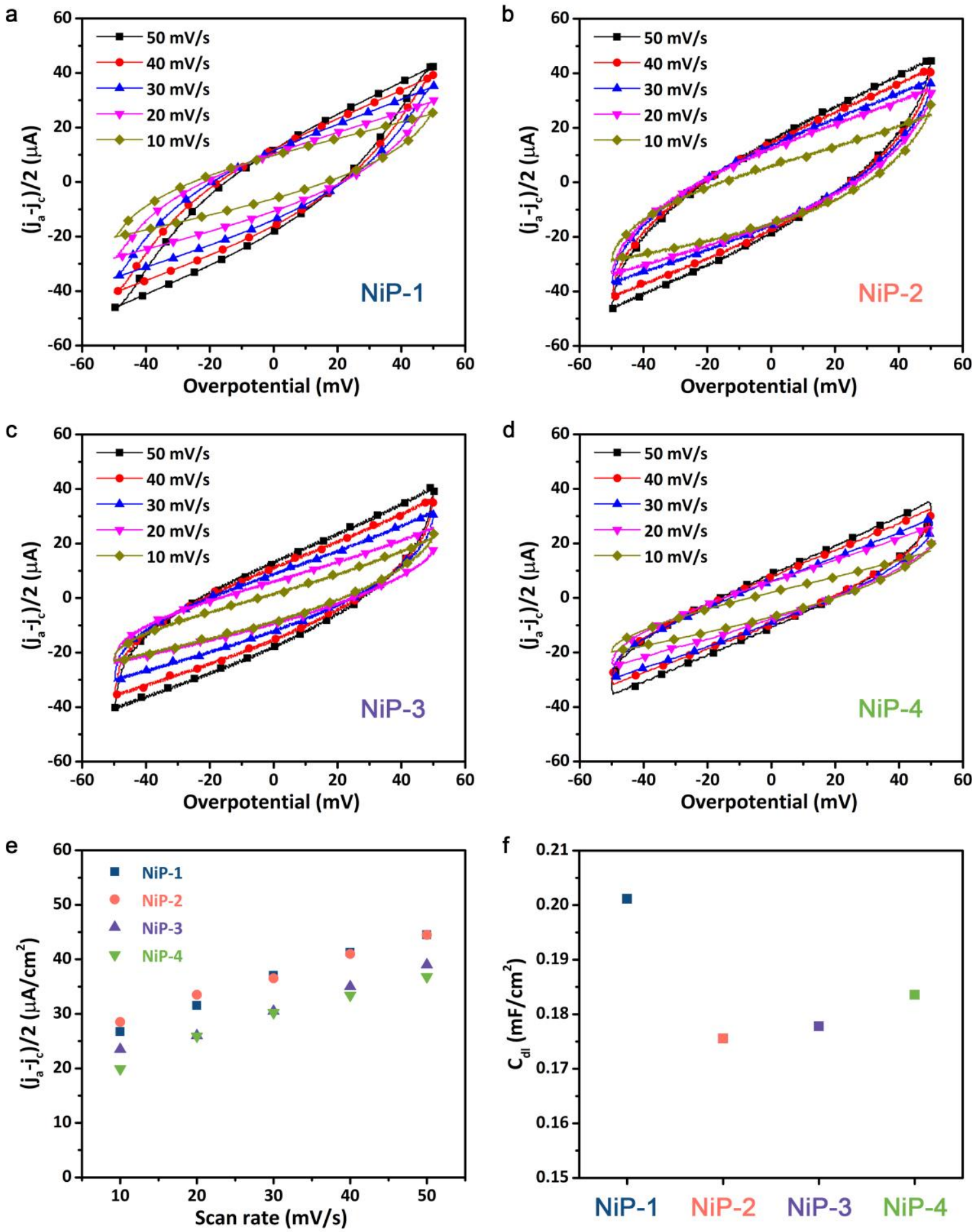

Figure S3. Cyclic voltammograms for (a) NiP-1, (b) NiP-2, (c) NiP-3, and (d) NiP-4 films. (e) The changes in $\left(\mathrm{j}_{\mathrm{a}}-\mathrm{j}_{\mathrm{c}}\right) / 2$ as a function of the scan rate of cyclic voltammetry obtained from (a)-(d) and (f) double-layer charging capacitance $\left(\mathrm{C}_{\mathrm{dl}}\right)$ of the NiP films. 
a
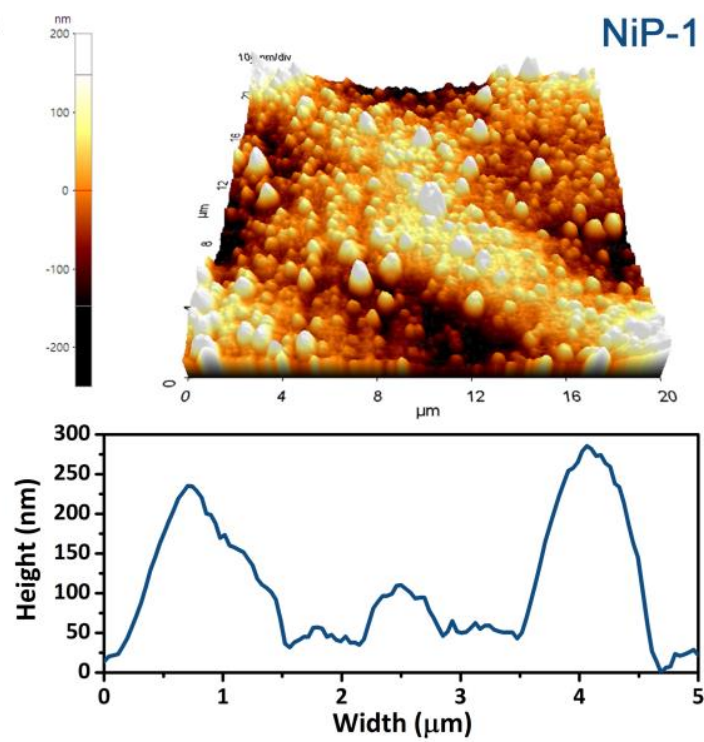

C
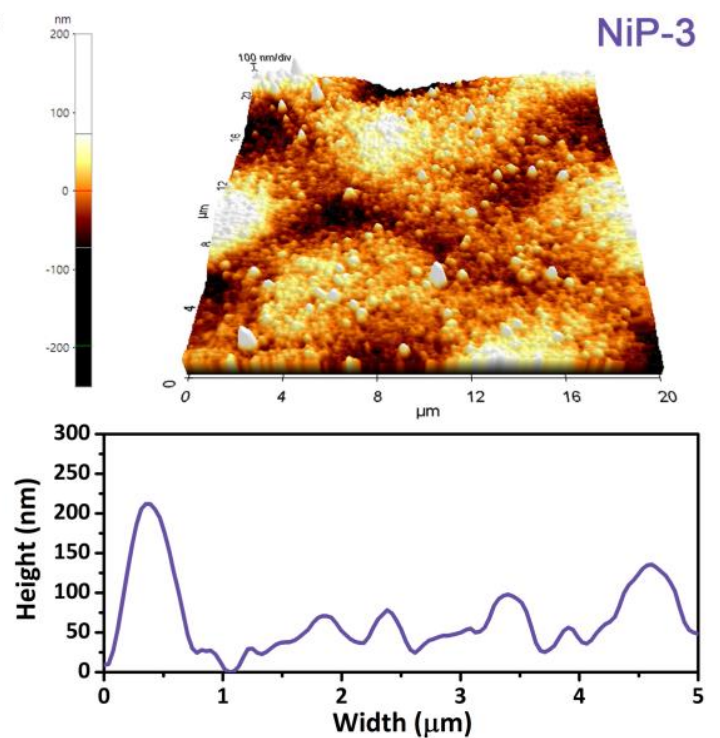

b
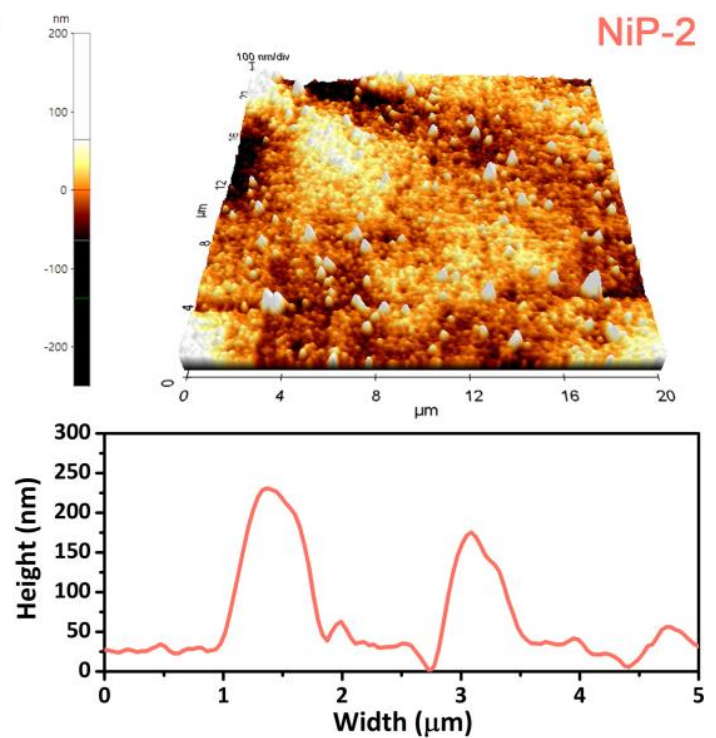

d
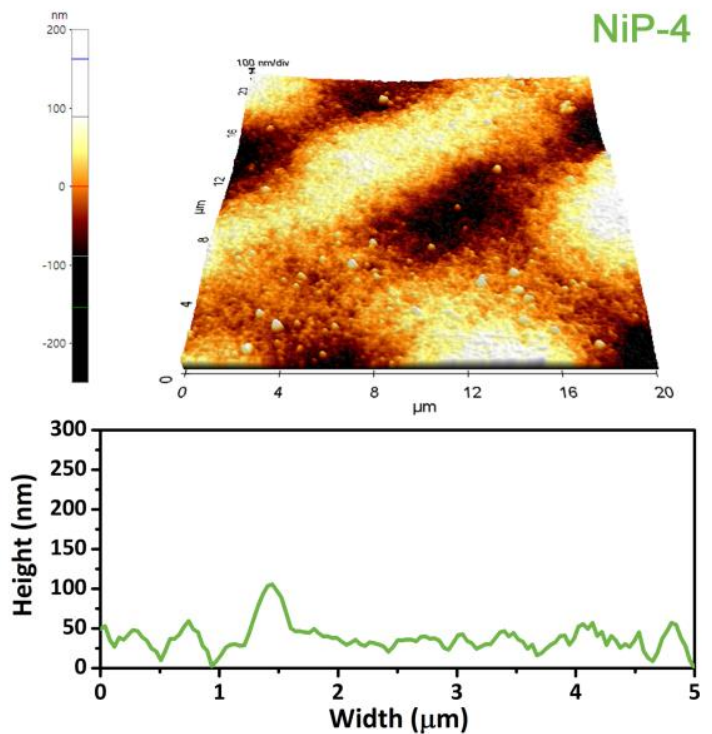

Figure S4. Surface morphology and typical line scanning profiles of (a) NiP-1, (b) NiP-2, (c) NiP3, and (d) NiP-4 films. 


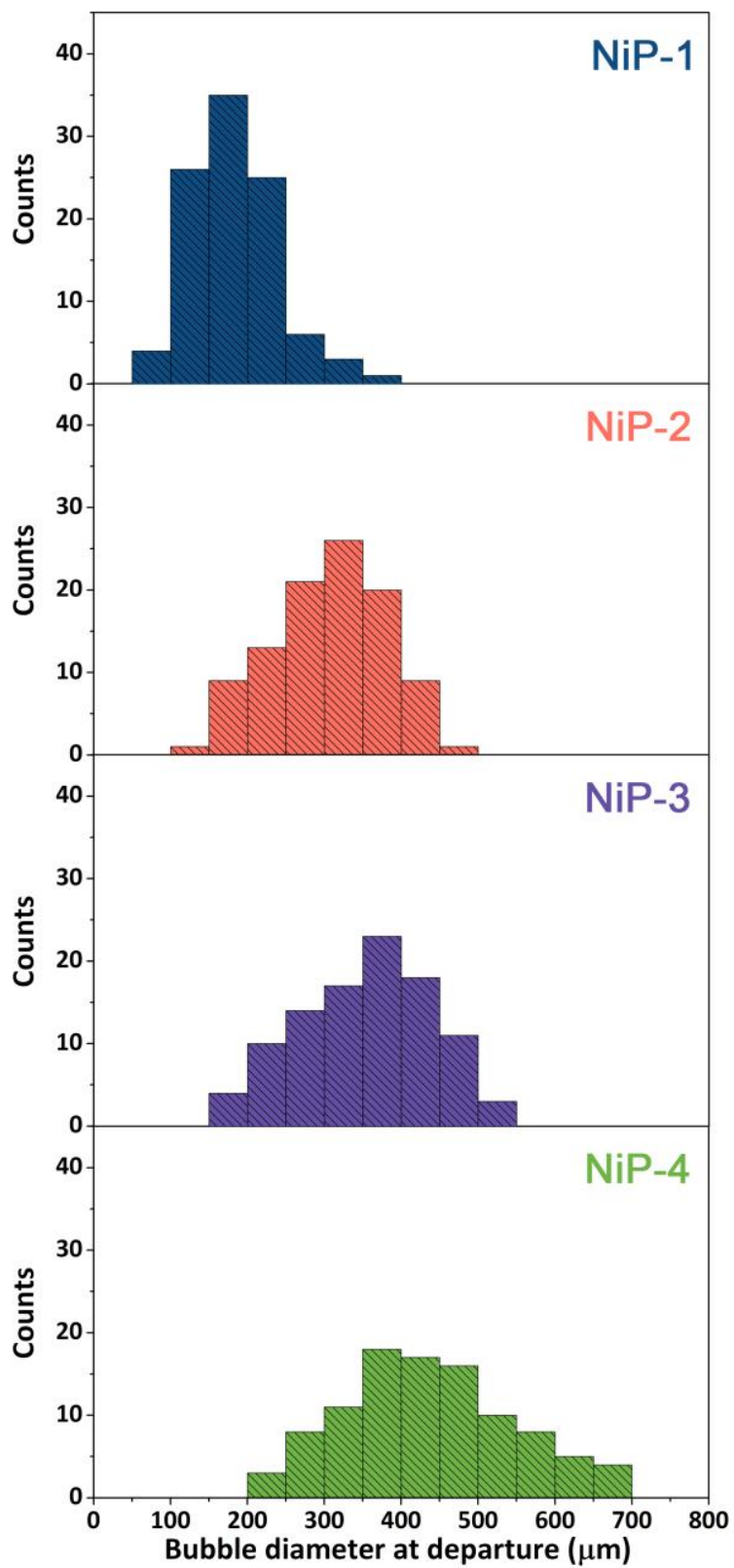

Figure S5. Size distribution of $\mathrm{H}_{2}$ bubbles on the NiP films in a horizontal electrode configuration. The bubble sizes were obtained from the images in Figure 5 and Video S1. 
a
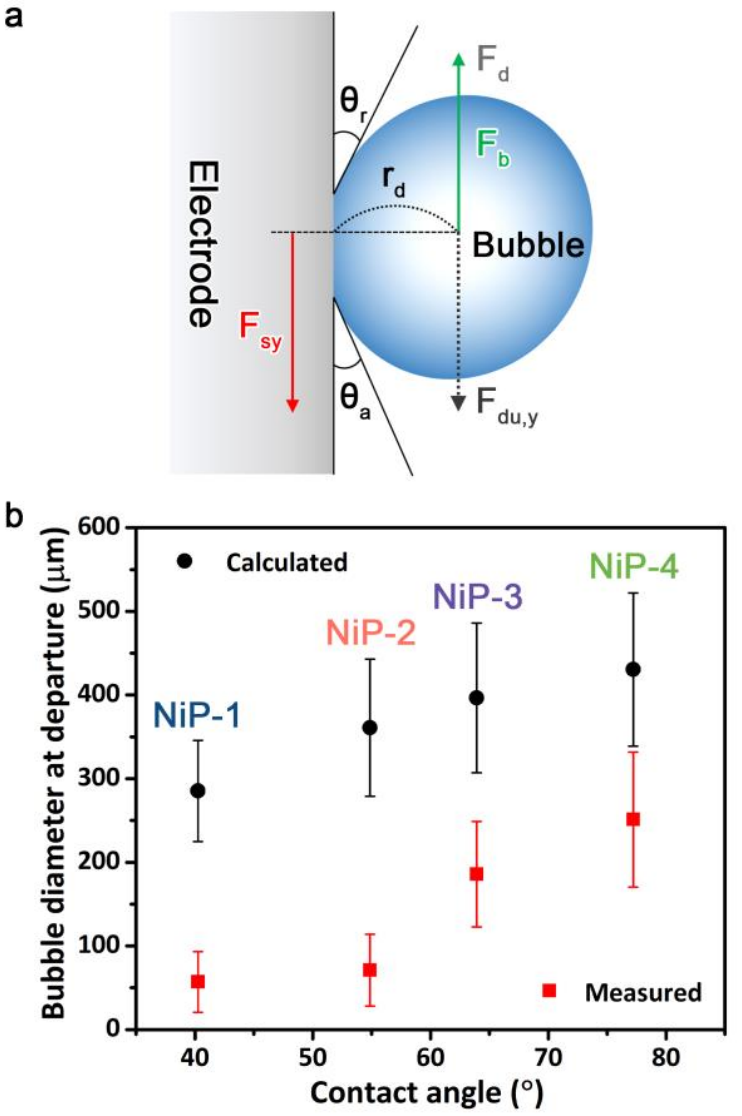

Figure S6. (a) Scheme of force balance model using a vertical electrode configuration and (b) bubble diameter at departure measured from the snapshots of Video S2 and calculated using Equation (S6) with respect to the water contact angle in a vertical electrode configuration. 

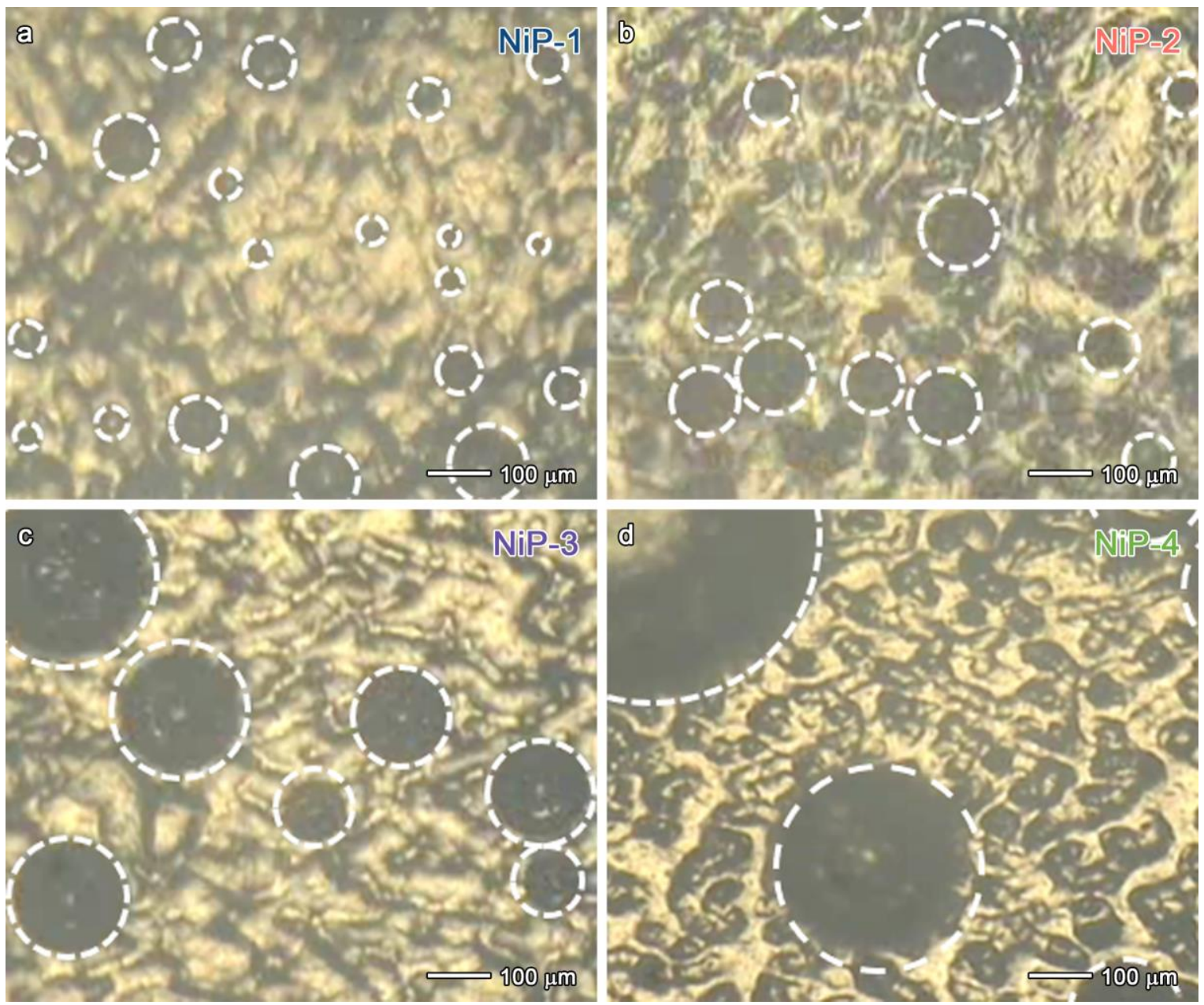

Figure S7. Snapshots for the generated $\mathrm{H}_{2}$ bubbles on (a) NiP-1, (b) NiP-2, (c) NiP-3 and (d) NiP4 films at the same current density of $-10 \mathrm{~mA} / \mathrm{cm}^{2}$, captured in Video S2. These results were obtained with a vertical electrode configuration. 


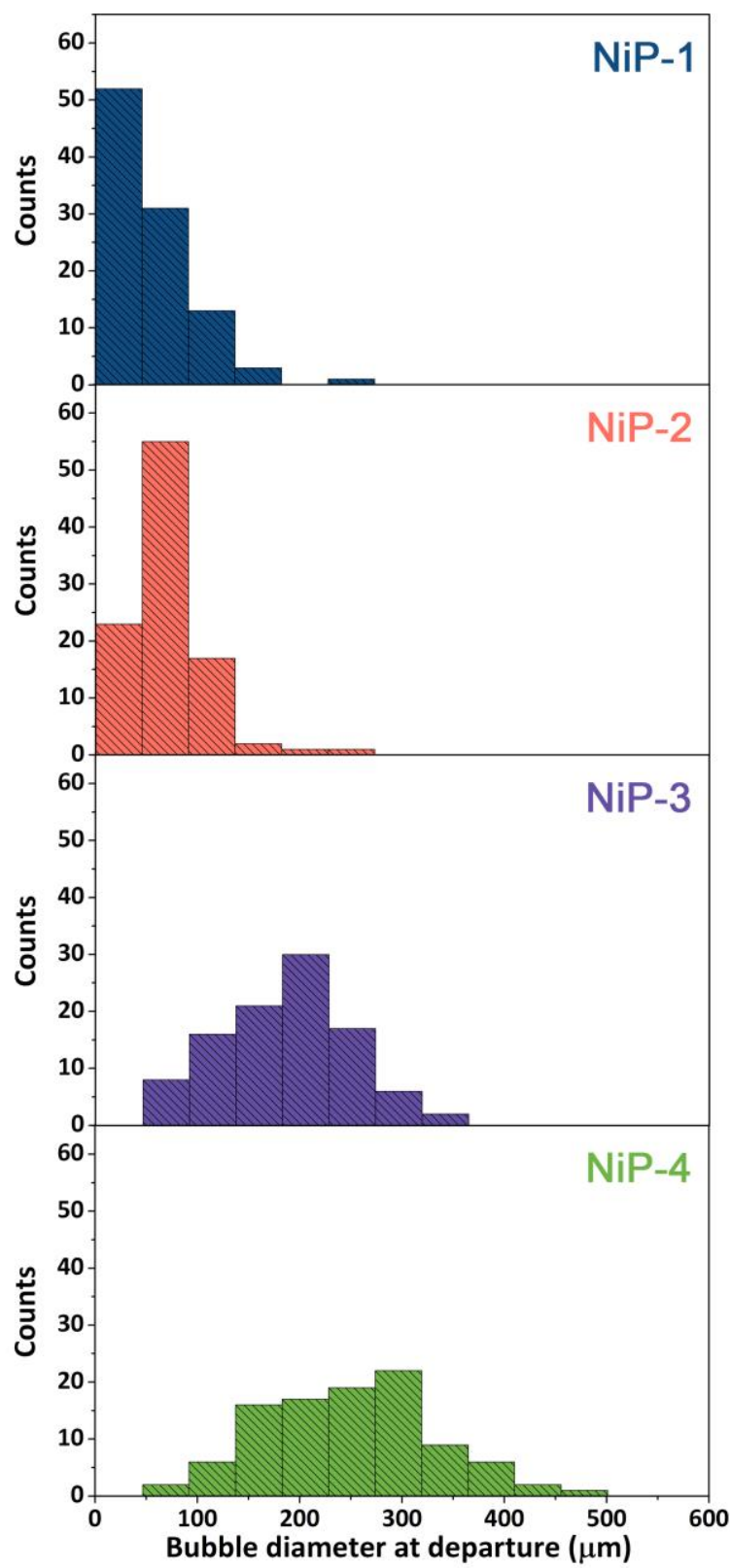

Figure S8. Size distribution of $\mathrm{H}_{2}$ bubbles on the NiP films in a vertical electrode configuration. The bubble sizes were obtained from the images in Figure S7 and Video S2. 


\section{Supplementary Table}

Table S1. Complexing Agents Used for NiP Electroless Deposition.

\begin{tabular}{c|ccc}
\hline \multirow{2}{*}{ Samples } & \multicolumn{3}{|c}{ Complexing Agents (mM) } \\
& Tartrate & Ethanolamine & Citrate \\
\hline NiP-1 & 250 & - & - \\
NiP-2 & - & 500 & - \\
NiP-3 & - & - & 300 \\
NiP-4 & - & - & 400 \\
\hline
\end{tabular}




\section{References}

(1) He, H. D.; Qu, N. S.; Zeng, Y. B.; Tong, P. Z. Improvement of Hydrogen Bubbles Detaching from the Tool Surface in Micro Wire Electrochemical Machining by Applying Surface Microstructures. J. Electrochem. Soc. 2017, 164 (9), E248-E259.

(2) Cho, Y. J.; Yum, S. B.; Lee, J. H.; Park, G. C. Development of Bubble Departure and Liftoff Diameter Models in Low Heat Flux and Low Flow Velocity Conditions. Int. J. Heat Mass Transf. 2011, 54 (15-16), 3234-3244.

(3) Klausner, J. F.; Mei, R.; Bernhard, D. M.; Zeng, L. Z. Vapor Bubble Departure in Forced Convection Boiling. Int. J. Heat Mass Transf. 1993, 36 (3), 651-662. 